\title{
Barriers and facilitators to exclusive breastfeeding practices in a disadvantaged community in southern Zimbabwe: A maternal perspective
}

Paddington T. Mundagowa ${ }^{1 *}$, Elizabeth M. Chadambuka ${ }^{2}$, Pugie T. Chimberengwa ${ }^{3}$ Fadzai Mukora-Mutseyekwa ${ }^{1}$

${ }^{1}$ Department of Clinical Research Centre, Africa University, Mutare, Zimbabwe

${ }^{2}$ Department of Health Sciences, Africa University, Mutare, Zimbabwe

${ }^{3}$ Ministry of Health and Child Care, Matabeleland North Province, Bulawayo, Zimbabwe

\section{*Corresponding author}

Address: Africa University Clinical Research Centre, 132 H. Chitepo Street, Mutare, Zimbabwe.

Mobile number: +263773878116

Email address: mundagowap@africau.edu 


\section{Abstract}

Background: Despite the well-documented significance of EBF in developing countries, many poor communities still present with the highest percentage of disease burden resulting from suboptimal breastfeeding.

Objectives: To identify the maternal perception on barriers and facilitators to EBF in Gwanda District, Zimbabwe.

Methods: Five focused group discussions were conducted using 40 purposively-selected mothers while eight in-depth key informant interviews were also conducted. The qualitative data collected were analyzed using thematic network analysis. The themes were used in interpreting the perceived barriers and facilitators of EBF.

Results: The study identified individual, socio-cultural, health service-related and environmental factors as the basic themes influencing maternal infant feeding choice. These were grouped into two organizing themes, namely, barriers and facilitators of EBF which were summarized into one global theme: EBF intention. Facilitating factors were maternal autonomy, self-efficacy, knowledge of EBF definition, maternal diet, support and sourcing information from healthcare workers. Poor infant feeding practices, affordability of alternative infant feeding options, ritualistic/symbolic infant preparations, family conflicts, increased workload and hot climate were barriers to EBF.

Conclusion: To increase in uptake of EBF in the study area required comprehensive multiple stakeholder interventions incorporating the mothers, influential family members, religion and traditional advisors, and healthcare workers.

Keywords: Maternal, Exclusive Breastfeeding, FGDs, Perceptions, Barriers, Facilitators, Thematic network analysis

\section{Background}

The World Health Organization (WHO) recommends that mothers should start breastfeeding within the first hour of childbirth and continue feeding the infant on only breastmilk up to six months before adding complementary feeding and water to the infant's diet [1]. Suboptimal breastfeeding escalates the risk of child morbidity and mortality, particularly in low-income settings $[2,3]$. Globally, optimal breastfeeding could lead to economic savings of up to US\$300 billion while averting the death of 823000 under-five children and 20000 mothers [4].

While breast milk is a natural and renewable food for the infant's first inoculation against death, ill-health and poverty, it is also delivered to the baby without contamination and without the need for unnecessary packaging $[5,6]$. The significance of exclusive breastfeeding (EBF) in low and middle-income countries is well-documented but the resource-limited sub-Saharan African region presents with the highest disease burden resulting from suboptimal breastfeeding when compared to the rest of the world [7].

In most African households, maternal infant feeding choices are profoundly reliant on cultural beliefs, gender dynamics and household related-factors [8-10]. Maternal knowledge of EBF, family pressure, socio-demographic factors, and place of delivery are also significant determinants in maternal infant feeding decisions [11]. Overall, families are the primary source of breastfeeding 
knowledge although the health system also plays a major role in the maternal decision on whether to exclusively breastfeed or not [12].

To promote six month EBF, the Zimbabwean government adopted robust Infant and Young Children Feeding (IYCF) and Baby-Friendly Hospital Initiative (BFHI) programs which were conducted with the help of partners like non-governmental organizations. However, despite these interventions, a study in Gwanda District reported a low EBF rate of 36 percent [13]. Besides the low EBF rate, a national Lot Quality Assurance Sampling survey of May 2017 identified Gwanda District as one of the 18 out of 60 districts that urgently needed infant nutrition monitoring and support [14]. Thus, infant nutrition in this impoverished southern part of the country was a major public health challenge and understanding the barriers and facilitators of EBF uptake could help identify information gaps that needed attention to improve infant nutrition in the district.

The aim of this study was to identify maternal perceptions on barriers and facilitators to six-month EBF in Gwanda District. Understanding these factors at individual and community levels could inform the designing of effective interventions specific for this and other similar populations. This has the potential to reduce the burden of poor infant nutrition by promoting the uptake of EBF to the WHO recommended target of at least $50 \%$ by 2025 [15].

\section{Methods}

\section{Study design}

The researchers used a qualitative approach by utilizing focus group discussions (FGDs) and indepth interviews for data collection during the period April to May 2018. Qualitative methods were used because of their strength to examine issues in detail and depth with participants. They were not restricted to specific questions, but were guided by the researchers [16]. Utilizing FGDs saves time and resources, and participant perceptions can be explored and clarified in real time [17]. Group discussions promote open participant interaction while simultaneously reducing the anxieties and pressure associated with individual interviews.

\section{Context}

The study was carried out in Gwanda District, Matabeleland South Province, Zimbabwe. The district had 30 health centers and 54 Extended Program of Immunization Outreach (EPIO) points. EPIO points are organized centers within a community where mothers brought their babies for routine immunization and growth monitoring. The mothers also received health education and counseling in family planning and infant feeding at the EPIO points. According to the Gwanda District schedule, the EPIO team visited each point at least once a month.

In 2018, Gwanda District had a population of 142 943, of which 3971 were children under one year old and 21027 children under five years. According to unpublished data from the Ministry of Health and Child Care (2017), the estimated population of women of childbearing age and expected annual births in the district were 32464 and 5775 , respectively. The district was mostly rural, characterized by limited access to health facilities, and poor nutrition and health indicators. Gwanda District is located in the hottest and driest region of the country, receiving very little annual rainfall. This result in poverty, poor agricultural yields and food insecurity in the area $[18$, 19]. The study area was mainly made up of the Ndebele ethnic group and IsiNdebele was the commonly used language. 


\section{Sampling}

Purposive sampling of EPIO points was done, targeting the inclusion of women from both urban and rural settings. Thus, the five focused group discussions (FGDs) were held at EPIO points, namely: Phakama (serving an urban community), Mandihongola, Selonga, Zelezele and Stanmore EPIO points (serving rural, mining and farming communities). These points were at least $30 \mathrm{~km}$ apart. The intention to conduct FGDs was communicated to mothers through the District Outreach Nurses who offered health services to the mothers. Researchers used the EPIO attendance register to identify women whose infants were aged 6-12 months (chosen to reduce problems with maternal recall). The mothers were purposively selected and approached face-to-face to ascertain their interest in participating in the discussion after they had received the intended health services. Accompanying caregivers who were not the mother of the baby and those mothers who refused to consent for the group discussion were excluded from the study. Forty women participated in the FGDs and their characteristics are presented in Table 1.

Table 1. Characteristics of focused group discussion participants

\begin{tabular}{|c|c|c|}
\hline Variable & Frequency $(\mathrm{N}=40)$ & Percentage (\%) \\
\hline \multicolumn{3}{|l|}{ Age category (years) } \\
\hline$<20$ & 10 & 25 \\
\hline $20-30$ & 17 & 42.5 \\
\hline $31-40$ & 6 & 15 \\
\hline$>40$ & 7 & 17.5 \\
\hline \multicolumn{3}{|l|}{ Mean age $=28 \pm 6.3$ years } \\
\hline \multicolumn{3}{|l|}{ Parity } \\
\hline $1^{\text {st }}$ child & 6 & 15 \\
\hline $2^{\text {nd }}$ child & 14 & 35 \\
\hline $3^{\text {rd }}$ child & 14 & 35 \\
\hline $4^{\text {th }}$ child & 0 & 0 \\
\hline$>4$ children & 6 & 15 \\
\hline \multicolumn{3}{|l|}{ Employment status } \\
\hline Formal/Informal & 10 & 25 \\
\hline None & 30 & 75 \\
\hline \multicolumn{3}{|l|}{ HIV Status } \\
\hline Positive & 6 & 15 \\
\hline Negative & 34 & 85 \\
\hline Mothers on anti-retroviral therapy & 6 & 15 \\
\hline \multicolumn{3}{|c|}{ Infant feeding practices when the baby was 0 to 6 months of age } \\
\hline Successfully practiced EBF & 9 & 22.5 \\
\hline Gave plain water and breastmilk & 31 & 77.5 \\
\hline Added solid foods & 20 & 50 \\
\hline \multicolumn{3}{|c|}{ A VHW visited the mother when the baby was between 0 to 6 months of age } \\
\hline Yes & 24 & 60 \\
\hline No & 16 & 40 \\
\hline
\end{tabular}


The key informants were five village health workers (VHWs) who were all women and five nutrition ward coordinators (NWCs) made up of two men and three women. The VHWs and NWCs were purposively selected from each selected EPIO point. The key informants were interviewed to get an overview of EBF practices and a structured key informant in-depth interview guide used that was specifically developed for this study. The interviews were conducted in IsiNdebele.

\section{Data collection procedure}

The research tools were designed by the authors and these were pretested for validity, reliability, and clarity at Pelele EPIO point using a sample size of six mothers who met the inclusion criteria. Questions and prompts used during the FGDs were derived from study objectives and perspectives which arose from the previous discussions and required further probing. Only the recruited mothers and researchers were present during the course of the FGDs.

Mothers who consented to participate in the study were interviewed briefly before the FGDs to ascertain their socio-demographic data, health status and infant feeding practices. Focused group discussions lasted between 60 and 90 minutes; PTM was the moderator and administered the questions to the groups of mothers, while two trained and oriented field assistants who were nurse midwives from outside the district instantly captured verbal narratives and non-verbal responses in the form of notes and voice recordings. The note-takers used their discretion to approximate the age of the narrating participant as teenage, young, middle-aged or older mother. These were used to label quoted narratives and give a sense of age-differentiated perceptions in the results section. Data saturation was achieved after the fifth FGD.

\section{Data analysis}

The data obtained from the field were mainly handwritten notes and audio taped messages which were transcribed verbatim. The transcribed data were translated from IsiNdebele to English with the help of two blinded linguistic experts. This study used the hermeneutical philosophy as the underpinning epistemological basis of analysis [20]. To organize and comprehend the qualitative data obtained, the researchers employed thematic network analysis [21].

According to Attride-Stirling (2001), thematic network analysis involves systematic extraction of basic, organizing and global themes from text. Basic themes which were simple lower-order premises characteristic of raw data offering very little meaning about the text were derived from the field notes. Identification of basic themes was followed by organizing them into more abstract clusters telling a similar story. These clusters or organizing themes simultaneously grouped narratives and dissected the core assumptions underlying a broader theme. Finally, the organizing themes precipitated into one primary theme with overarching interpretation-the global theme, summarizing and making sense of basic and organizing themes as supported by the textual data.

Before analysis, the two field workers, PTM and PTC read the text repeatedly until they felt acquainted with the data. To reduce the complex volumes of data during the thematic network analysis, manual data coding was conducted with guidance from the research questions. Systematic exploration of recurrent issues was arranged into meaningful and manageable text segments of quotations, phrases and words. To limit the scope and focus of codes, the researchers were meticulous to avoid redundancy and flexible to avoid missing vital data. Themes were then abstracted from the coded text segments before being refined to improve specificity. Similar and coherent themes were assembled into two organizing themes of barriers and facilitators of EBF. The grouped barriers and facilitators became the thematic networks where themes from the coded 
text were utilized as basic themes in creating the networks. An iterative process of drifting between the coded text and the themes during data analysis ensured that consistency and quality were maintained.

To sustain the validity, data triangulation was done by comparing data obtained from the FGDs and in-depth interviews. Participant narrative quotes were employed to support text interpretation and FDG codes. FGD 1, FGD 2, FGD 3, FDG 4 and FGD 5 for Zelezele, Mandihongola, Selonga, Stanmore, and Phakama EPIO points, respectively were added for identification of the place where the FGD was conducted.

\section{Ethical considerations}

Ethical clearance to carry out this study was obtained from Africa University Research Ethics Committee and permission was given by the Ministry of Health and Child Care through the office of the Provincial Medical Director for Matabeleland South Province. Participation was voluntary.

\section{Results}

Maternal narratives were either aligned with positive traits that promoted EBF (perceived facilitators) or negative traits that undermined EBF (perceived barriers). These produced two organizing themes, namely: barriers and facilitators of EBF. The organizing themes then precipitated into a global theme: the intention to practice six-month EBF.

\section{Individual level}

\section{Facilitators at individual level}

Perceived maternal awareness of EBF benefits either from a previous childbirth or a relative/friend who succeeded in six-month EBF promoted EBF during the recent childbirth. The mothers described increased confidence due to personal experience from prior EBF success or learned skill from peers. As self-efficacy increased, breastfeeding became easier and EBF seemed more natural. Planning to practice EBF while pregnant reinforced a mother's resolve to sustain the practice up to six months post-delivery.

"I planned to exclusively breastfeed my baby when I was pregnant so I started by getting information from my neighbor who was also feeding her baby on breast milk only. She took me through her experiences, which was quiet a roller coaster. I became so determined to accept the challenges of EBF as opportunities and the benefits as rewards. I am proud that I made the right decisions and here is my second healthy baby."- young mother, FGD 3.

The ability of a woman to make her own autonomous decisions aided in the promotion of EBF as independent single mothers and those whose partners allowed them to decide could easily make the EBF choice.

"As married women we sometimes have limited capacity to decide on many household issues, however I am blessed to have an understanding husband who allows me to make the decision on infant feeding matters, otherwise the majority of women who can easily make the choice are single mothers."- young mother, FGD 2.

The investigators asked the mothers to define EBF to have a preliminary view of the women's knowledge of the practice. Mothers narrated the benefits of the six-month EBF especially convenience and cost-effectiveness of the practice. The babies who were exclusively breastfed 
were seen as healthier than mixed-fed babies due to high nutrient content and the immunity from the mothers' milk.

"EBF refers to feeding the baby on breastmilk only, no porridge and other solid foods from birth until the baby attains six months of age." - young mother, FGD 5.

"Breastmilk contains all the nutrients required for the growth of the baby. Solids can be hard to digest and (it) damages the tender digestive system of the infant"-- middle-aged mother, FGD 1.

Mothers strongly believed that an HIV positive woman could transmit the virus to the newborn baby if she practiced mixed feeding; hence prevention of mother-to-child transmission (PMTCT) resulted in HIV positive women exclusively breastfeed their babies. The perceived threat of HIV infection to the newborn baby led to an increase in uptake of the EBF practice by seropositive mothers.

"Nurses and VHWs say that if you are HIV positive, you can prevent transmission of the virus to the baby by feeding the baby on breastmilk only for the first six months of life.' I have two mothers that I know who are taking HIV pills and their babies seem to be doing well because they don't give them any other food."- older mother, FGD 1.

\section{Barriers at individual level}

Some women felt that the six-month EBF was impractical and they would opt to EBF for one to three months post-delivery. This was mainly due to poor self-efficacy explanations, namely: producing insufficient breast milk due to size of breast and above normal weight of the baby at birth. Mothers queried about the feasibility of producing enough breast milk by women who had smaller breasts. Some participants narrated struggling to produce sufficient breast milk which could be sustained for the first six months particularly for babies who weighed above normal birth weight at delivery. Babies who had above normal birth weight were reported to be incessant wailers thus, complementary feeding was most likely to be introduced before the age of six months.

"It can be difficult for mothers who have small breasts to produce sufficient breast milk for a long period like six months and I think they should try maybe two or three months of EBF, not six!"young mother, FGD 2.

"At first, I wanted to follow the nurse's recommendations but my baby was a 'big baby', he wailed day and night. I was afraid that he was going to develop chest pains... After giving him mealiemeal porridge and water at three weeks, the wailing gradually ceased" -young mother, FGD 5.

"Big babies latch on for hours and it's difficult to judge whether they are full or not."- middle aged mother, FGD 1.

A considerable number of women mentioned that EBF included giving plain water to the child. Such assumptions may be due to a belief that plain water is harmless because it does not constitute any calorific value, hence it would not interfere with EBF. Water from the tap or borehole was considered safe and it was not boiled or treated before it was given to the baby.

"Of course an infant needs water, everyone needs water to survive. We have always known that from tradition... my baby also had hic-cups problems and tap water solved it for me. "-adolescent mother, FGD 5. 
A lot of male partners in this community had gone to South Africa in search of employment and they send monthly groceries to their wives in Gwanda. The groceries often included infant formula if there was a baby in the family. Participants reported that the community generally revered the use of infant formula as a sign of opulence. The community believed that formula feeding was a sign of achievement. Therefore, they could "choose to bottle feed their infants if they were rich enough to afford the formula milk."

"I have a rich aunt who bottle-feeds her infant with formula milk. Her baby is big and I think breastfeeding could be a thing of the past if all mothers could afford formula milk"- adolescent mother, FGD 2.

Some women misinterpreted PMTCT as the major drive towards practicing EBF which resulted in a mistaken belief that EBF was only for HIV positive mothers who wanted to protect their infants from contracting the virus. This potentially deterred HIV negative mothers who would have planned to EBF their infants for six-months fearing that they could be stigmatized as HIV positive by their communities.

"When I went for my first ANC (Ante-natal Clinic) visit, the nurses over emphasized why it was important to exclusively breastfeed the infant if you are HIV positive. To me, she sounded more like she was saying it is still safe for the HIV negative mother not to practice EBF"-older mother, FGD 4.

"I was pregnant when I told my sister-in-law that I was considering EBF. She was shocked and asked if my husband (her brother) knew about my HIV positive status. I told her that I was HIV negative but she could not believe it even after I showed her the ANC booklet confirming the negative result."-middle aged mother, FGD 3.

\section{Socio-cultural level}

\section{Facilitators at socio-cultural level}

A mother's decision the infant feeding choice was influenced by the custodians of local tradition (older family members) and religious leaders. Breastfeeding women were encouraged to take salty foods such as roasted groundnuts or roasted maize; as this was believed to stimulate milk production therefore facilitate the six-month long EBF. Eating salty foods induces thirst and the mother would drink more fluids necessary for breastmilk production. Many participants agreed that this advice worked well and could be used by mothers who reported producing insufficient breastmilk for the baby.

"My grandmother advised me to use salted nuts to promote milk production and I was thrilled because of how the advice worked. I think mothers struggling to produce breast milk should try it!'”-young mother, FGD 2.

"Whenever I eat roasted groundnuts, breastfeeding becomes a lot easier for me and the baby"older mother, FGD 1.

Many mothers received moral support from family members. Supportive partners, mothers-in-law and other family members were perceived as pillars of strength in providing emotional and financial support, thereby facilitating EBF. 
"My husband in South Africa sends groceries and money to sustain us every month. He insists that my responsibility is to make sure that the children are well fed and I don't need to go around working in other people's fields for survival"-a young woman, FGD 1.

"I live with two aunts and they are very supportive because they help out on daily house chores and I have more time to breastfeed the baby"-a young woman, FGD 4.

\section{Barriers at a socio-cultural level}

Religious prescriptions, especially by 'men of God' dominated in all the three FGDs. Family members, especially partners and grandmothers, encouraged women to give ritualistic concoctions 'imithi yesintu' which were believed to enhance the chances of the baby's survival. Mothers reported that some apostolic and African traditional religions within the Gwanda community recommended their congregants to give infants 'prophylactic preparations' such as boiled cooking oil and crushed plant roots/leaves. These were believed to defend the babies from 'inkanda'/depressed fontanel and evil spirits, hence improving the baby's chances of survival. Thus, married women had to conform to the patrimonial family infant feeding demands and religious recommendations for fear of being labeled as iconoclastic.

"Sometimes we want to follow what the nurses teach but it is difficult to deny the church elders to treat the baby of 'imithi yesintu' to protect the baby from evil spirits...Imagine you refuse and then the baby later dies! You would feel guilty and everyone would blame the infant's death on you (the mother). "-adolescent mother, FGD 2.

"We have a challenge in putting the message through to family elders because they believe we are imposing the Western culture on their children by telling them to stop giving traditional preparations to the infant"-nutrition ward coordinator, Zelezele.

There was a common belief that the milk produced when the mother is pregnant causes diarrhea and can even be fatal for the breastfeeding baby. Thus, becoming pregnant while breastfeeding was perceived as a threat to the baby being nursed and a reason to stop breastfeeding altogether.

"If you want to save the life of your lactating baby, it's always wise to immediately stop breastfeeding as soon as you realize that you are pregnant. Otherwise, all of the babies who continue to breastfeed from a pregnant mother become sick. "-middle-aged mother, FGD 2.

"The breastmilk that a pregnant mother produces lacks nutrients and I think it is best to wean-off the lactating baby and consider complementary feeding when you find out that you are pregnant"young mother, FGD 2.

"You can continue to breastfeed as long as other people don't know that you are pregnant. Once somebody discovers that you are pregnant, the lactating baby will become sick."-young mother, FGD 1.

Poverty and lack of economic opportunities in Gwanda fueled family conflicts that sometimes ended up in domestic violence and maternal depression which are barriers to the success of the six-month EBF.

"Every time I quarrel with my husband, I become stressed and breastfeeding becomes a mammoth task. I have noticed that the baby also struggles to get adequate milk during such times" -middle aged mother, FGD 3. 


\section{Health service delivery level}

\section{Facilitators at a health service delivery level}

The investigators also wanted to know the source of breastfeeding knowledge and participants mentioned female family members such as mother-in-law and aunties as the primary source while VHWs and nurses at the clinic were regarded as secondary sources. Most mothers trusted breastfeeding education from health workers because they provided dependable rationale when the mothers probed the importance of EBF.

"Our mothers and grandmothers have a lot of experience on breastfeeding at the same time we are really thankful to the nurses who provide edifying reasons for why we should breastfeed exclusively"-older mother, FGD 3.

There was a widespread belief that ANC and VHW visits were beneficial and such engagements were perceived as facilitators of EBF in the district. Mothers expressed their gratitude for the community-based VHWs although they also reported that the few available VHWs were overwhelmed with other health programs demanding their attention. The scarcity of VHWs was a major cause of concern.

"Proactive pregnant mothers who go for routine checkup visits get to know how others are managing and learn more from other women. VHWs have the information and are making a great difference in educating mothers on good infant feeding practices such as $E B F^{\prime \prime}$-older mother, FGD 3.

"I live far from the clinic, so I depend on VHWs for information on infant feeding, breastfeeding, and baby caring in general"-young mother, FGD 2.

\section{Barriers at a health services level}

The mothers also described how the health workers had limited time to entertain all of the women's concerns because they were short staffed and overwhelmed by heavy workloads. This was despite the use of VHWs to bridge the gap in providing EBF knowledge. Most mothers believed the nurses had more information hence they would have comprehensive answer on EBF from facility nurses than VHWs. Participants also reported having limited knowledge concerning expressing breastmilk.

"The $[E B F]$ information from the nurses is really helpful. The problem is that on an average day, we are attended by a single nurse at the clinic. She (the nurse) is not able to give all the EBF information because of the long patient waiting queues. Once you miss the morning health talks, that's it."- young mother, FGD 2.

"Nurses at the clinic rarely talk about expressing breast milk to us. I think they assume that since most of us are full-time housewives, we have all the time to breast feed the baby. Maybe they are afraid that we don't have the right resources to preserve the milk once we express or they just presume we don't like it (expressing milk). I think they should just give us the knowledge, then we can make an individual decision"'-young mother, FGD 4. 


\section{Environmental level}

\section{Barriers at an environmental level}

The climate is characterized by hot weather, with mean average temperature of $40^{\circ} \mathrm{C}$ and some mothers believe that breastmilk alone is insufficient to hydrate the baby. Mothers who drink less fluids could become dehydrated and this hinders the flow of breastmilk, eventually leading to a struggle to sustain the six-month EBF.

"The Gwanda climate is very hot, frankly breastmilk alone cannot be able to keep the baby hydrated for six months"-middle-aged mother, FGD 3.

"I breastfeed my baby on breastmilk only but my mother-in-law always complains that the baby will get dehydrated. I heard she occasionally gives water to the baby when I was away"-a young mother, FGD 1.

"It is very hot in Gwanda and a breastfeeding mother needs to take more fluids to rehydrate her body in order to promote milk production and maintain the flow of breast milk. The mothers practice the opposite by giving the water to the babies"- NWC, Phakama.

\section{EBF intention}

This study used the two organizing themes to interpret the global theme-EBF intention. The decision on whether to breastfeed exclusively or not depends on complex and multifaceted mechanisms. Successful EBF was a product of maternal motivation, availability of supportive structures and maternal comprehension of the facilitators, even though the woman was surrounded by a plethora of barriers challenging her decision to opt for the optimal infant feeding option-EBF.

Figure 1 displays the thematic network of perceived barriers and facilitators of six-month EBF as narrated by the study participants, while Table 2 provides a summary of the facilitating factors and barriers to EBF in Gwanda District.

\section{Discussion}

This study aimed to identify the maternal perceptions on the barriers and facilitators of six-month EBF in the Gwanda District using FGDs. Results from the discussions yielded multiple basic themes that influenced EBF and these included: individual, socio-cultural, health services and cultural factors. Grouping of the basic themes was done according to two organizing themes, namely, barriers and facilitators of EBF which themes were interpreted as one global theme: EBF intention.

The FGDs revealed gaps in the maternal knowledge of the EBF practice as evidenced by some participants narrating either an incomplete or incorrect definition of EBF. Only $23 \%$ of the FGD participants practiced EBF. although most mothers correctly identified the advantages of EBF. There is a need to interpret this finding with care because of the qualitative nature of the study and the purposive sampling. The brief maternal interview openly asked whether the mother had exclusively breastfed her baby or not, leaving mothers who did not entirely understand the definition of EBF to potentially give a wrong answer. 


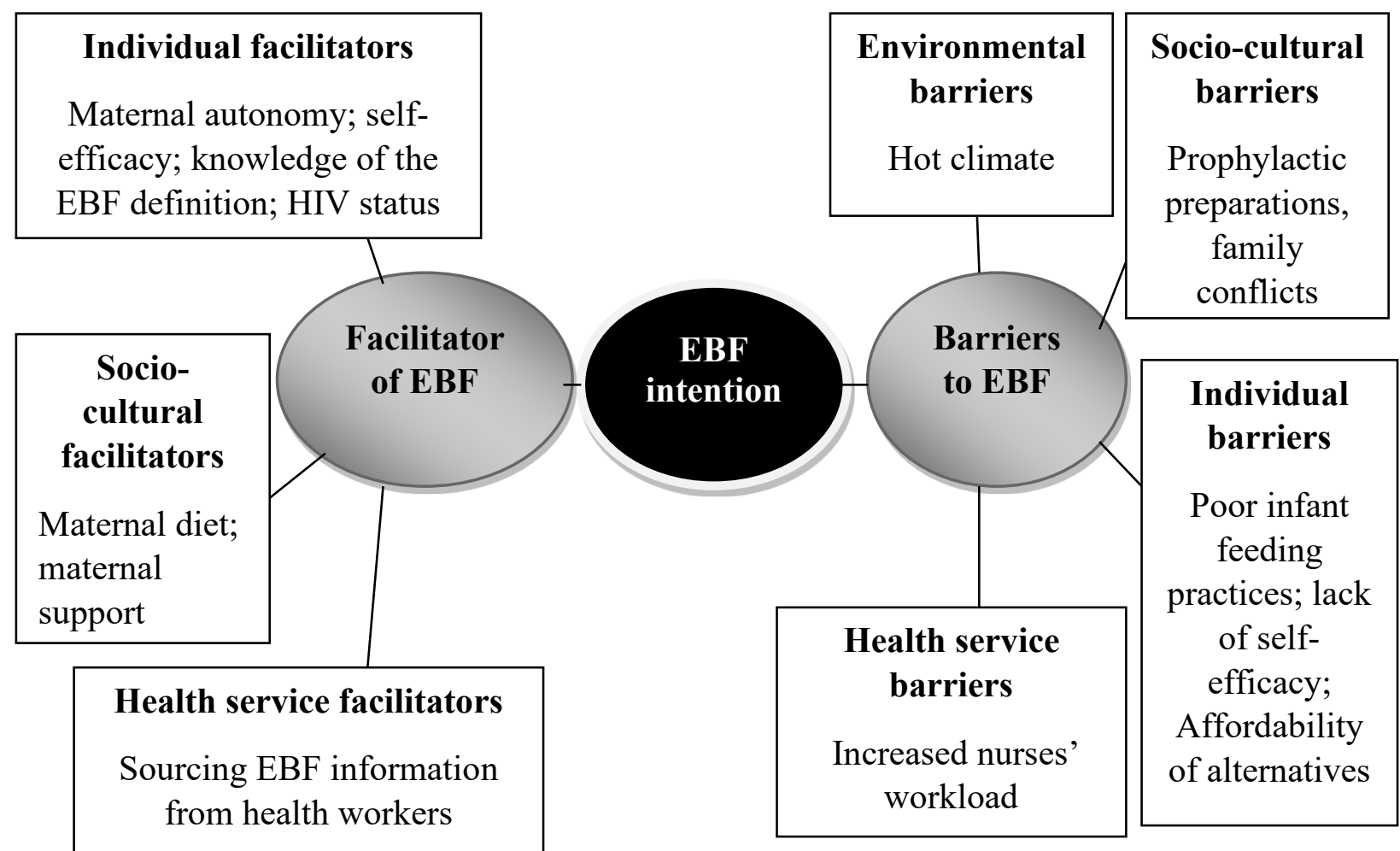

Figure 1. Thematic network of the perceived barriers and facilitators of EBF among mothers.

Table 2. Summary of the facilitating factors and barriers to EBF in Gwanda District

\begin{tabular}{|c|c|}
\hline Facilitators of EBF & Barriers of EBF \\
\hline 1.Maternal awareness of the benefits of EBF & 1. Poor maternal self-efficacy \\
\hline $\begin{array}{l}\text { 2. Maternal confidence from a previous EBF } \\
\text { success }\end{array}$ & 2. Baby above normal birth weight \\
\hline $\begin{array}{l}\text { 3. Maternal ability to make an autonomous } \\
\text { decision }\end{array}$ & $\begin{array}{l}\text { 3. An understanding that giving the baby wa- } \\
\text { ter cannot interfere with EBF }\end{array}$ \\
\hline $\begin{array}{l}\text { 4. Prevention of mother-to-child transmission } \\
\text { of HIV }\end{array}$ & 4. Infant feeding is a sign of opulence \\
\hline $\begin{array}{l}5 . \text { Good maternal dietary recommendations } \\
\text { by elders }\end{array}$ & $\begin{array}{l}\text { 5. Misinterpretation of prevention of mother- } \\
\text { to-child transmission of HIV }\end{array}$ \\
\hline 6. Moral support from family members & 6. Religious rituals \\
\hline $\begin{array}{l}\text { 7. Getting infant feeding advice from VHWs } \\
\text { and nurses }\end{array}$ & 7. Poverty \\
\hline \multirow[t]{2}{*}{ 8. Regular ANC and VHW visits } & $\begin{array}{l}\text { 8. Poor infant feeding counselling due to in- } \\
\text { creased work burden on the health providers }\end{array}$ \\
\hline & 9. Hot climate \\
\hline
\end{tabular}


Palmér and Ericson (2019) described breastfeeding as a journey navigated by the mother to find one's unique pathway in which some mothers navigated smoothly while others struggled [22]. This study revealed similar findings, as women who had planned to EBF during pregnancy would seek for relevant advice to help them navigate the EBF journey and continued to fight on despite confrontation by multiple barriers. Breastfeeding is not easy and natural for many mothers, as the practice challenges maternal self-efficacy [23,24]. Enduring the six-month EBF journey was also perceived as a way to fulfill set prenatal breastfeeding expectations [25]. Self-confidence and selfefficacy are psychological factors that substantially predict the intention to EBF [26, 27].

Maternal perceptions of breastmilk insufficiency were also revealed in studies conducted in Ghana and Zimbabwe [10, 28]. The 'insufficient milk' syndrome encourages premature addition of complementary feeding to the infant's diet $[29,30]$. Quantifying the breastmilk produced is subject to maternal or an infant feeding advisor's perception. However, scientific inquiries have shown that a mother continues to produce enough quantity and quality of breast milk for up to six months even when the mother is consuming a minimal diet, and despite the size of their breasts [31, 32]. In some instances, mothers failed to differentiate a 'hunger cry' from a general baby cry [33]. Messages targeting improved EBF rates should orient mothers to breastfeed as per any rising need both during the day and at night. Thus they should not wait until they suspect that the baby is crying from hunger. Mothers should also be wary of other factors that would make the baby cry for example discomfort due to heat or inflammation.

Participants identified EBF as a proven measure for PMTCT and this was consistent with a South African prospective cohort study [27]. However, participants who were HIV negative felt that EBF was compulsory for HIV positive mothers while optional to HIV negative mothers. A local study on experiences and challenges of EBF also noted that mothers narrated mixed and confusing messages regarding breastfeeding and HIV transmission [28]. Conflicting messages on breastfeeding by health workers in the context of HIV often lead to disharmony of EBF practice $[34,35]$. Health workers should emphasize the importance of EBF to both seronegative and seropositive mothers.

Study participants believed in giving their infants traditional concoctions/'imithi yesintu' to prevent incidences of a depressed fontanelle/'inkanda' and other ailments. The practice of giving herbal medicine was often encouraged by respected household elders [28, 36, 37]. These traditional practices done mainly for ritual and symbolic reasons act as barriers to EBF and are important considerations when planning interventions to promote EBF in the community.

Some women submitted their infant feeding choice decision to the household because they felt obligated to do so even though they knew EBF was the best feeding choice for their baby. This finding was supported by Joseph and Earland [12] who stated that the "motivation to sustain EBF was influenced by the conflict between the obligation to perform traditional rites and maternal awareness of the benefits of EBF". Targeting the mother-child dyad alone is thus not sufficient, given that the maternal decision on whether to EBF or not is also influenced by husbands/partners and elders/custodians of tradition/religion. Breastfeeding enhancement programs should involve the male counterparts, grandparents and significant others to improve maternal conformity at the household level.

This study also identified that the women perceived breastfeeding while pregnant as not safe for the lactating baby. This finding was similar to other studies in rural Ghana and Zimbabwe [10,38]. Mothers believed that getting pregnant while the baby is still young 'spoils' the breastmilk causing 
illness or death to the infant. Such beliefs were a threat to EBF in mothers who become pregnant before the lactating baby reaches six months milestone. It has long been shown that pregnancy during true exclusive breastfeeding is extremely rare [39]. Nevertheless, messages aimed at improving EBF practice need to emphasize on continuing breastfeeding even when the mother becomes pregnant within the six months post-delivery period.

Furthermore, some participants believed feeding the infant with formula milk was a sign of affluence and the babies who were fed on such milk were healthier. This finding was similar to a study by Rosenberg et al. who reported that mothers thought formula milk was healthier despite having knowledge of the advantages of breastfeeding [40]. Such beliefs could be attributed partly to exposure to infant formula adverts which appear to upraise the quality of their products when compared to breast milk. Although our study objectives did not include the male partner perspectives, a study in Uganda found out that men felt EBF was a sign of poverty which was a sign of the breadwinner's failure to provide food for the baby [41]. Therefore education aimed at promoting EBF must also include the partners/husbands.

The study revealed that a supportive family environment can be a facilitator to EBF. Supportive husbands and family were identified as key individuals in helping to take care of the baby as well as maternal emotional and psychosocial support [28, 42]; while lack of support from some family members such as grandmothers and husbands were barriers to successful EBF [43, 44]. Participants mentioned that sometimes poverty gives rise to partner violence, a finding that was consistent to that of a study by Slabbert who noted that poverty limits choices and resources and women become in low-income settings become vulnerable to domestic violence [45]. Since the relationship between the inhabitants of households differs widely in Gwanda, broader community campaigns could help in educating all family members on the importance of providing support to the breastfeeding mothers.

Mothers identified ANC and VHW visits as a source of vital breastfeeding information. Knowledge of the advantages of EBF is usually dispatched via routine ANC visits, as concluded in a South African study [27]. These visits give health workers more time to counsel mothers on optimal breastfeeding and empower them in refuting contrary advice and messages from family members and friends. Many women in this study did not practice EBF, although the majority of them had counseling and support visits from a VHW, and this signal either a gap between knowledge and the motivation to practice EBF or the VHWs did not prioritize EBF messages during the visits.

Since babies are not able to tell the mother that they are thirsty, mothers in Gwanda assumed that it was necessary and justified to give the baby plain water due to the local hot climate. Giving the baby plain water and breast milk was also wrongfully considered to be part of EBF. This finding was consistent with another Zimbabwean study which revealed the discord caused by using the term EBF instead of a more precise term "fed exclusively on breast milk" [28]. The belief that infants need water to quench their thirst is still common in Zimbabwe and other regions in Africa $[43,45]$. Interventions to promote EBF need a more clear-cut locally relevant definition which the mothers can easily assimilate and breastfeeding education must emphasize how breastmilk production is based on demand and supply, not the weather. Exclusively breastfed infants do not require additional water even in hot weather $[46,47]$ 


\section{Strengths and limitations}

This study involved mothers of 6-12 month old infants which is the period immediately after the six months cut-off for EBF. This helped in reducing recall bias among the participants. Our study also included mothers of different ages, residences, and marital statuses, thus providing a broad range of perspectives. This was a qualitative study that was based on a small sample that was purposively selected, thus limiting the generalizability of the findings. Using FGDs may have led to the provision of socially desirable responses.

\section{Conclusions}

The study identified how the different barrier and facilitating factors influenced the maternal intention to opt for EBF. Understanding the variations in maternal EBF experiences aides in appreciating the uniqueness of each woman's circumstance in order to prioritize individualized care for the breastfeeding mothers. The complex decisions regarding infant feeding require multiple stakeholder interventions, including the mothers, influential family members, religious and traditional advisors, and healthcare workers. From the findings of this study, the development of system-wide interventions to realign maternal, health system, and community perceptions towards supporting EBF mothers is recommended.

\section{Abbreviations}

$\mathrm{ANC}$

BFHI

$\mathrm{EBF}$

EPIO

FGDs

HIV

IYCF

NWCs

PMTCT

VHWs

WHO
Antenatal clinic

Baby-friendly hospital initiative

Exclusive breastfeeding

Extended program of immunization outreach point

Focused group discussions

Human immune-deficiency virus

Infant and young child feeding

Nutrition ward coordinators

Prevention of mother-to-child transmission of HIV

Village health workers

World Health Organization 


\section{References}

1. World Health Organization. Global Nutrition Targets 2025: breastfeeding policy brief (WHO/NMH/NHD/14.7). Geneva: World Health Organization. 2014. https://www.who.int/nutrition/publications/globaltargets2025 policybrief breastfeeding/ en/

2. Black RE, Victora CG, Walker SP, Bhutta ZA, Christian P, de Onis M, et al. Maternal and child undernutrition and overweight in low-income and middle-income countries. The Lancet. 2013;382(9890):427-51.

3. Rollins NC, Bhandari N, Hajeebhoy N, Horton S, Lutter CK, Martnes JC, et al. Why invest, ad what it will take to improve breastfeeding practices? The Lancet. 2016;387(10017):491-504.

4. The Lancet. Breastfeeding: achieving the new normal. The Lancet. 2016;387(10017):404. https://doi.org/10.1016/s0140-6736(16)11210-5

5. Hansen K. Breastfeeding: a smart investment in people and economics. The Lancet. 2016;387(10017):416. https://doi.org/10.1016/s0140-6736(16)00012-X

6. Victora CG, Bahl R, Barros AJD, França GVA, Horton S, Krasevec J, et al. Breastfeeding in the $21^{\text {st }}$ century: epidemiology, mechanisms, and lifelong effects. The Lancet. 2016;387(10017):475-490. https://doi.org/10.1016/S0140-6736(15)01024-7

7. United Nations Children's Fund/World Health Organization. Diarrhea: why children are still dying and what can be done, New York, USA: UNICEF/WHO; 2010.

8. Issaka AI, Agho KE, Page AN, Burns P, Stevens GJ, Dibley MJ. Determinants of early introduction of solid, semi-solid or soft foods among infants aged 3-5 months in four Anglophone West African Countries. Nutrients. 2014;6(7):2602-2618. Doi: 10.3390/nu6072602

9. Napier AD, Ancarno C, Butler B, Calabrese J, Chater A, Chatterje A, et al. Culture and health. The Lancet. 2014;384(9954):1607-39.

10. Otoo GE, Lartey AA, Pérez-Escamilla R. Perceived incentives and barriers to exclusive breastfeeding among peri-urban Ghanaian women. J Hum Lact. 2009;25(1):34-41. Doi: $10.1177 / 0890334408325072$

11. Khasawneh W, Khasawneh AA. Predictors and barriers of breastfeeding in north of Jordan: could we be better? Int Breastfeed J. 2017;12:49. Doi: https://doi.org/10.1186/s13006-017-0140-y

12. Joseph FI, Earland J. A qualitative exploration of the sociocultural determinants of exclusive breastfeeding practices among rural mothers, North West Nigeria. Int Breastfeed J. 2019;14(38). Doi: https:/doi.org/10.1186/s13006-019-0231-z

13. Mundagowa PT, Chadambuka EM, Chimberengwa PT, Mukora-Muteyekwa F. Determinants of exclusive breastfeeding among mothers of infants aged 6 to 12 months in Gwanda District, Zimbabwe. Int Breastfeed J. 2019;14(1). Doi: 10.1186/s13006-0190225-x

14. Ministry of Health and Child Care Zimbabwe. Report on nutrition monitoring in 18 emergency districts using lot quality assurance sampling. MOHCC, Harare. May 2017.

15. UNICEF/WHO. Breastfeeding Advocacy Initiative. 2016. https://www.unicef.org/nutrition

16. Anderson C. Presenting and evaluating qualitative research. American Journal of Pharmaceutical Education. 2010;74(8):141. Doi: 10.5688/aj7408141. 
17. Goodman C, Evans C. Focus groups. In: Gerrish, K, Lacey, A. (Eds). The research process in nursing. $6^{\text {th }}$ Edition. USA: Blackwell Publishing; 2013. pp. 358-368.

18. Moyo R, Love D, Mul M, Mupangwa W, Twomlow S. Impact and sustainability of lowhead drip irrigation kits, in the semi-arid Gwanda and Beitbridge Districts, Mzingwane Catchment, Limpopo Basin, Zimbabwe. Phys Chem Earth. 2006;31(15-16):885-892.

19. Munamati M, Nyagumbo I. In situ rainwater harvesting using dead level contours in semo-arid southern Zimbabwe: Insights on the role of socio-economic factors on performance and effectiveness in Gwanda District. Phys Chem Earth. 2010;35(1314):699-705.

20. Dahlberg K, Dahlberg H, Nyström M. Reflective lifeworld research. 2. Ed. Lund: Studentlitteratur; 2008. pp. 23-94.

21. Attride-Stirling J. Thematic networks: an analytic tool for qualitative research. Qualitative Research. 2001;1:385-405.

22. Palmér L, Ericson J. A qualitative study on the breastfeeding experience of mothers of preterm infants in the first 12 months after birth. Int Breastfeed J. 2019;14(35).

23. Doyle N. "The highest pleasure of which Woman's nature is capable": breastfeeding and the sentimental maternal ideal in America, 1750-1860. J Am Hist. 2011;97(4):958-73.

24. Phillips KF. First-time breastfeeding mothers: perceptions and lived experiences with breastfeeding. Int J Childbirth Educ. 2011;26(3):18-22.

25. Gregory EF, Butz AM, Ghazarian SR, Gross SM, Johnson SB. Met expectations and satisfaction with duration: a patient-centered evaluation of breastfeeding outcomes in the infant feeding practices study II. J Hum Lact. 2015;3(3):444-51.

26. Bosnjak P, Rumboldt M, Stanojevic M, Dennis CL. Psychometric assessment of the Croatian version of the breastfeeding self-efficacy scale-short form. J Hum Lact. 2012;28:565-9.

27. Jama NA, Wilford A, Masango Z, Haskins L, Coutsoudis A, Spies L, Horwood C. Enablers and barriers to success among mothers planning to exclusively breastfeed for 6 months: a qualitative prospective cohort study in Kwazulu Natal, South Africa. Int Breastfeed J. 2017;12(43). Doi: 10.1186/s13006-017-0135-8

28. Nduna T, Marais D, van Wyk B. An Explorative Qualitative Study of experiences and challenges of exclusive breastfeeding among mothers in rural Zimbabwe. Infant, Child, \& Adolescent Nutrition. 2015;7(2). Doi: https://doi.org/10.1177/1941406414568562

29. Zakar R, Zakar MZ, Zaheer L, Fischer F. Exploring parental perceptions and knowledge regarding breastfeeding practices in Rajanpur, Punjab Province, Pakistan. Int Breastfeed J. 2018;13(24). Doi: 10.1186/s13006-018-0171-z

30. Diji AK, Bam V, Asante E, Lomotey AY, Yeboah S, Owusu HA. Challenges and predictors of exclusive breastfeeding among mothers attending the child welfare clinic at a regional hospital in Ghana: a descriptive cross-sectional study. Int Breastfeed J. 2016;12(13). Doi: 10.1186/s13006-017-0104-2

31. Dettwler KA, Fishman C. Infant feeding practices and growth. Annual Review of Anthropology. 1992;21:171-204.

32. Renner JK, Adewole AO, Apena M. The relationship between breast size and breast milk volume of nursing primipara. Nigerian Quarterly Journal of Hospital Medicine. 2008;14(1). Doi: 10.4314/nqjhm.v14i1.12688 
33. Goosen $\mathrm{C}, \mathrm{McLachlan} \mathrm{MH}$, Schübl C. Infant feeding practices during the first 6 months of life in a low-income area of Western Cape Province. SAJCH. 2014;8(2):50-54. Doi: 10.7196/sajch.675

34. Fjeld E, Siziya S, Kapeta-Bwalya M, Kankasa C, Moland KM, Tylleskär T, et al. 'No sister, the breast alone is not enough for my baby': a qualitative assessment of potentials and barriers in the promotion of exclusive breastfeeding in southern Zambia. Int Breastfeed J. 2008;3:26.

35. Mkotwana P, Steenkamp L, Von der Marwitz J. Challenges in the implementation of the Infant and Child Feeding Policy to prevent mother-to-child transmission of human immunodeficiency virus in Nelson Mandela Bay District. South African Journal of Clinical Nutrition. 2013;26(2);75-82.

36. Maonga AR, Mahande MJ, Damian DJ, Msuya SE. Factors affecting exclusive breastfeeding among women in Muheza District Tanga Northeastern Tanzania: A mixed method community based study. Maternal Child Health Journal. 2016;20:77-87. Doi: 10.1007/s10995-015-1805-z

37. Thepha T, Marais D, Bell J, Muangpin S. Perceptions of northeast Thai breastfeeding mothers regarding facilitators and barriers to six-month exclusive breastfeeding: focus group discussions. Int Breastfeed J. 2018;13(14). Doi: https://doi.org/10.1186/s13006$\underline{018-0148-y}$

38. Cosminsky S, Mhloyi M, Ewbank D. Child feeding practices in a rural area of Zimbabwe. Social Science \& Medicine. 1993;36(7):937-947. Doi: 10.1016/02779536(93)90085-i

39. Kennedy KI, Rivera R, McNeilly AS. Consensus statement on the use of breastfeeding as a family planning method. Contraception. 1989 May 1;39(5):477-96.

40. Rosenberg KD, Eastham CA, Kasehagen LI, Sandoval AP. Marketing infant formula through hospitals: the impact of commercial hospital discharge packs on breastfeeding. American Journal of Public Health. 2008;98(2):290-295. Doi: 10.2105/AJPH.2006.103218

41. Engebretsen IM, Moland KM, Nankunda J, Karamagi CA, Tylleskär T, Tumwine JK. Gendered perceptions on infant feeding in Eastern Uganda: continued need for exclusive breastfeeding support. Int Breastfeed J. 2010;5(13). Doi: https://doi.org/10.1186/17464358-5-13

42. Jama A, Gedreyesus H, Wubayehu T, Gebregyorgis T, Teweldemedhin M, Berhe T, et al. N. Exclusive breastfeeding for six months of life and its associated factors among children aged 6-24 months in Burao District, Somaliland. Int Breastfeed J. 2020;15(5). Doi: https://10.1186/s13006-020-0252-7

43. Barnes BS, Perngparn U. Exclusive breastfeeding experiences among mothers in Bangkok, Thailand: findings from a mix-methods study. Journal of Health Research. 2013;27(1):19-25.

44. Tsegaye M, Ajema D, Shiferaw S, Yirgu R. Level of exclusive breastfeeding practice in remote and pastoralist community, Aysaita woreda, Afar, Ethiopia. Int Breastfeed J. 2019;14(6). Doi: https://doi.org/10.1186/s13006-019-0200-6

45. Slabbert I. Domestic violence and poverty: some women's experiences. Research on Social Work Practice. 2016;27(2):223-230. 
46. Kamudoni PR, Maleta K, Shi Z, de Paoli MM, Holmboe-Ottesen G. Breastfeeding perceptions in communities in Mangochi district in Malawi. Acta Paediatr. 2010;99(3):367-372. Doi: 10.1111/j.1651-2227.2009.01603.x

47. Almroth S, Bidinger PD. No need for water supplementation for exclusively breast-fed infants under hot and arid conditions. Trans R Soc Trop Med Hyg. 1990;84:602-604.

48. Cohen RJ, Brown KH, Rivera LL, Dewey KG. Exclusively breastfed, low birthweight term infants do not need supplemental water. Acta Paediatr. 2000;89(5):550-2.

\section{Declarations}

\section{Ethics approval and consent to participate}

Ethical clearance to carry out this study was obtained from Africa University Research Ethics Committee (Ref: 315/17) and permission was given by the Ministry of Health and Child Care through the office of the Provincial Medical Director for Matabeleland South Province. Participants were asked to willingly sign a consent form upon agreeing to be part of a group discussion. Mothers were invited for an FGD after receiving intended health services at the outreach point and participation was voluntary. Adolescent mothers under the age of 18 were considered "emancipated minors" who were independent to make adult decisions, hence were allowed to sign for their consent to participate.

\section{Availability of data and materials}

The dataset used and/or analyzed during the current study are available from the corresponding author on a reasonable request.

\section{Competing interests}

The authors declare that they have no competing interests.

\section{Funding}

None

\section{Authors' contributions}

Study conception, design and data collection were done by PTM. PTM, EMC, PTC \& FNNM were involved in data analysis and interpretation. PTM wrote the draft article which was reviewed by all authors. All authors read and approved the final manuscript

\section{Acknowledgments}

We would like to thank The Provincial Medical Director of Matabeleland South Province for permission to undertake this study and the research assistants whose efforts were priceless in data acquisition and analysis. We are also grateful to the Gwanda District health staff members and mothers who participated in the FGDs. 